\title{
ESTUDO DA SOLUBILIDADE E RESISTÊNCIA MECÂNICA DE PARTÍCULAS DE PECTINA, QUITOSANA E VINHAÇA PARA USO COMO BIOFERTILIZANTE
}

\author{
G. O. RAGAZZO ${ }^{1}$, N. L. SANTOS ${ }^{1}$, S. R. BETTANI ${ }^{1}$, M. R. SOARES $^{1}$ e M. A. DA SILVA ${ }^{1}$ \\ ${ }^{1}$ Universidade Federal de São Carlos, Centro de Ciências Agrárias (CCA/UFSCar) \\ E-mail para contato: gab.ragazzo@hotmail.com
}

\begin{abstract}
RESUMO - A vinhaça é o principal resíduo da indústria sucroalcooleira, estando disponível em grandes quantidades. Sua principal destinação é na fertirrigação em plantações próximas às usinas. Porém, quando aplicada em grandes quantidades, o solo não consegue reter todos os íons presentes, podendo causar salinização do solo e/ou lixiviar, contaminando lençóis freáticos. O uso de biopolímeros em sistemas de liberação controlada/lenta tem emergido como alternativa ao uso de polímeros sintéticos para aplicações na agricultura. Pectina e quitosana são polissacarídeos naturais, biodegradáveis, não tóxicos, com boas propriedades de formação de géis. Esse estudo propõe o desenvolvimento e a avaliação da solubilidade e da resistência mecânica de partículas de pectina/quitosana e vinhaça. As partículas foram avaliadas quanto ao tamanho médio, massa solubilizável (MS) em água e em solução de cloreto de cálcio $0,01 \mathrm{M}$ e resistência à compressão. As partículas de pectina e vinhaça obtiveram um diâmetro médio de $266 \mathrm{~mm}$, massa solubilizável de 0,64 e 0,48 g MS/g massa seca em água e em $\mathrm{CaCl}_{2}$ 0,01 M, respectivamente, e força na compressão de 35,31 N, enquanto que as partículas de quitosana e vinhaça tiveram um diâmetro médio de $194 \mathrm{~mm}$, solubilidade de 0,49 e $0,34 \mathrm{~g} \mathrm{MS} / \mathrm{g}$ massa seca em água e em $\mathrm{CaCl}_{2}$ 0,01 $\mathrm{M}$, respectivamente, e força na compressão de 62,37 N. Essas partículas podem representar alternativas interessantes para o uso da vinhaça como biofertilizante.
\end{abstract}

\section{INTRODUÇÃO}

O desenvolvimento de tecnologias alternativas que aumentem a produtividade de alimentos sem causar impactos negativos aos ecossistemas representa um desafio atual e urgente considerando o cenário de crescimento da população mundial (Tomlinson, 2011). Neste contexto, o uso de fertilizantes tem uma contribuição essencial para a sustentabilidade da agricultura. Diversos tipos de fertilizantes, naturais e sintéticos, para uso na agricultura estão disponíveis no mercado em grandes quantidades (Naz e Sulaiman, 2016). Do ponto de vista do processo produtivo, o nitrogênio $(\mathrm{N})$, o fósforo $(\mathrm{P})$ e o potássio $(\mathrm{K})$ são os mais importantes, denominados macronutrientes primários. Fertilizantes nitrogenados, devido a sua mobilidade no solo, devem ser fornecidos às plantas de maneira controlada, de forma a tornar a aplicação mais eficiente possível. Pesquisas têm demonstrado que a adição de fertilizantes em matrizes poliméricas reduz a lixiviação de N e K de solos bem drenados (Ibrahim et al., 2015). Polímeros biodegradáveis extraídos de fontes renováveis, como carboidratos e proteínas, vêm se destacando como matrizes, alternativas aos polímeros sintéticos, para a 
construção de sistemas de liberação controlada com foco na agricultura. Dentre os polímeros naturais que se apresentam como potenciais formadores de hidrogéis destacam-se a pectina e a quitosana. Estes polissacarídeos são abundantes na natureza e de fácil extração (Fang et al., 2008).

A vinhaça constitui-se no líquido proveniente da destilação da solução alcoólica obtida do processo de fermentação do caldo de cana-de-açúcar, do melaço ou da mistura dos dois. A proporção de 10 litros de vinhaça por litro de etanol é a média representativa da atual tecnologia de produção, sendo a água residuária mais expressiva do setor sucroenergético. É rica em nutrientes, com quantidades apreciáveis de potássio, cálcio e magnésio; tem baixo pH, elevadas DBO e DQO, cor escura e odor característico. Sua principal utilização é na fertirrigação de culturas agrícolas, entretanto, as dosagens dependem das características do solo, pois quando aplicada em excesso, pode ocorrer lixiviação de íons, sobretudo nitrato e potássio, causando a contaminação de águas subterrâneas (Christofoletti et al., 2013).

O solvente normalmente utilizado para a formação de partículas de pectina e de quitosana é a água, sendo necessário abaixar o pH da solução para solubilização e gelificação dos polímeros. Desta forma, o uso da vinhaça como solvente na produção de partículas de pectina e/ou quitosana representa uma alternativa para o aproveitamento deste resíduo e a possibilidade de reciclagem de nutrientes como fertilizante. Neste sentido, este trabalho propõe o desenvolvimento de partículas de pectina e quitosana utilizando vinhaça como solvente, bem como a avaliação da solubilidade e da resistência mecânica à compressão das partículas obtidas.

\section{MATERIAL E MÉTODOS}

\subsection{Processo de obtenção das partículas}

Para a confecção das partículas foram utilizadas pectina cítrica de alto teor de metoxilação (ATM) (Genu tipo B Rapid Set-Z, CPKelco) e quitosana de massa molar média (Sigma-Aldrich). Cloreto de cálcio dihidratado em solução de etanol e tripolifosfato de sódio foram utilizados como agentes reticulantes das partículas de pectina ATM e de quitosana, respectivamente. A vinhaça foi coletada diretamente das colunas de destilação, a $95^{\circ} \mathrm{C}$, em uma indústria sucroalcooleira da região de Araras/SP e levada ao laboratório para acondicionamento (congelamento a $-20^{\circ} \mathrm{C}$ ) e caracterização físico-química. Carbono orgânico total (TOC) e nitrogênio total (TN) foram determinados em analisador TOC/TN Shimadzu ${ }^{\circledR}$. As demais determinações foram realizadas segundo Da Glória e Rodella (1972).

As soluções poliméricas foram preparadas através da adição da quantidade adequada dos biopolímeros (5 g de pectina ATM ou $3 \mathrm{~g}$ de quitosana) em $100 \mathrm{~mL}$ do solvente apropriado (vinhaça in natura ou água destilada). Os solventes tiveram seu $\mathrm{pH}$ ajustado para 3,0 (soluções de quitosana) ou 3,5 (soluções de pectina) com ácido acético glacial $0,1 \mathrm{~N}$. Após a adição dos biopolímeros, o sistema foi mantido sob agitação magnética constante por 1 hora, até completa dissolução e homogeneização do material.

A obtenção das partículas foi realizada pela técnica de gotejamento da solução de biopolímero $(30 \mathrm{~mL})$ em solução reticulante $(100 \mathrm{~mL})$ sob agitação por $30 \mathrm{~min}$. Para as partículas contendo pectina, a solução reticulante utilizada foi solução de cloreto de cálcio $1 \%$ 
em etanol $98 \%$ e para quitosana solução de tripolifosfato de sódio 5\%. Uma agulha (BD Slomed, diâmetro: $0,70 \times 30 \mathrm{~mm}$ ) foi acoplada a uma mangueira de silicone ligada a uma bomba peristáltica para controle da vazão de gotejamento da solução. A altura de gotejamento foi padronizada em $10 \mathrm{~cm}$ desde a ponta da agulha até a superfície da solução reticulante. As etapas do sistema de gotejamento estão ilustradas na Figura 1. As concentrações das soluções e demais parâmetros do processo foram definidos em etapas preliminares.

Figura 1 - Esquema do sistema para produção das partículas de pectina, quitosana e vinhaça

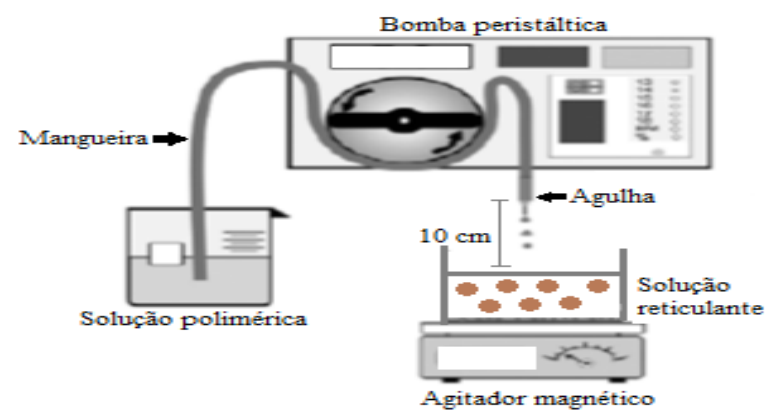

Após a formação e estabilização das partículas, estas foram secas em estufa com circulação forçada de ar (Marconi, MA035, Brasil) a $30^{\circ} \mathrm{C}$ por $24 \mathrm{~h}$. As partículas foram acondicionadas à temperatura ambiente e umidade relativa de $52 \%$ (controlada com solução de nitrato de magnésio) por 3 dias, antes da realização dos ensaios de caracterização.

\subsection{Caracterização das partículas}

Aspecto visual e diâmetro médio: a avaliação do aspecto visual foi realizada de forma subjetiva, considerando aspectos como formato, homogeneidade e presença de bolhas de ar. $\mathrm{O}$ diâmetro médio foi determinado pela medição de 10 partículas de cada tratamento, sendo feitas 2 medidas em cada partícula, utilizando-se o Software Image $\mathbf{J}^{\circledR}$.

Massa solubilizável (MS): foi quantificada segundo método proposto por IrissinMangata et al. (2001), com modificações. Inicialmente, a umidade de uma amostra (0,3 g) de partículas foi determinada $\left(105^{\circ} \mathrm{C} / 24 \mathrm{~h}\right)$. Uma outra amostra $(0,3 \mathrm{~g})$ foi pesada e então imersa em $100 \mathrm{~mL}$ de água destilada e/ou em solução de cloreto de cálcio $\left(\mathrm{CaCl}_{2}\right) 0,01 \mathrm{M}$, e mantida sob agitação de $100 \mathrm{rpm}$ por 24 horas em uma mesa agitadora orbital (Solab, SL-180/D, Brasil). O material restante foi recolhido por filtração em um papel filtro previamente seco e tarado. A massa seca final foi obtida após secagem em estufa a $105^{\circ} \mathrm{C} / 24 \mathrm{~h}$. A massa solubilizável foi determinada pela relação entre a massa seca inicial e após imersão em água.

Resistência à compressão: foi determinada utilizando-se um texturômetro TA.XT2 (Stable Microsystems SMD, Inglaterra). A compressão foi realizada em temperatura ambiente até $70 \%$ de deformação da amostra a uma velocidade de compressão de $1 \mathrm{~mm} . \mathrm{min}^{-1}$, conforme proposto por Tomović et al. (2015). A distância entre o probe e a placa plana foi ajustada em $10 \mathrm{~mm}$. Dez partículas de cada amostra foram comprimidas e a força máxima foi determinada. 


\subsection{Análises estatísticas}

A análise estatística dos dados foi efetuada por meio de análise de variância e do teste de Scott-Knott, a fim de determinar diferenças significativas entre as médias, a um nível de significância de 5\% (p<0,05). O software RStudio 3.2.4 (The R Foundation for Statistical Computing Platform, 2016) foi utilizado para esses cálculos.

\section{RESULTADOS E DISCUSSÃO}

Os resultados da caracterização físico-química da vinhaça utilizada nos experimentos estão apresentados na Tabela 1. Os resultados encontrados estão de acordo com as faixas de composição química média da vinhaça produzida a partir da fermentação de diferentes mostos à base de cana-de-açúcar (Soares et al., 2014).

Tabela 1 - Caracterização físico-química da vinhaça integral utilizada nos experimentos.

\begin{tabular}{|c|c|}
\hline Parâmetro & Resultado \\
\hline $\mathrm{pH}$ & 4,45 \\
\hline Sólidos Totais & $26,76\left(\mathrm{~g} \mathrm{~L}^{-1}\right)$ \\
\hline Nitrogênio Total & $222,4\left(\mathrm{mg} \mathrm{L}^{-1}\right)$ \\
\hline Carbono Orgânico total & $4074,0\left(\mathrm{mg} \mathrm{L}^{-1}\right)$ \\
\hline Fósforo & $800\left(\mathrm{mg} \mathrm{L}^{-1} \mathrm{P}_{2} \mathrm{O}_{5}\right)$ \\
\hline Potássio & $5700\left(\mathrm{mg} \mathrm{L}^{-1} \mathrm{~K}_{2} \mathrm{O}\right)$ \\
\hline Cálcio & $5100\left(\mathrm{mg} \mathrm{L}^{-1} \mathrm{CaO}\right)$ \\
\hline Magnésio & $4600\left(\mathrm{mg} \mathrm{L}^{-1} \mathrm{MgO}\right)$ \\
\hline Sulfato & $\left.500\left(\mathrm{mg} \mathrm{L}^{-1} \mathrm{SO}\right)_{4}\right)$ \\
\hline
\end{tabular}

O aspecto visual das partículas obtidas no presente estudo pode ser observado na Figura 2. Em geral, as partículas apresentaram matriz polimérica homogênea e formatos esféricos bem definidos, com exceção da partícula de pectina ATM utilizando água destilada como solvente, que apresentou formato de disco (achatado) conforme pode ser observado na Figura 2 D. As partículas de quitosana com vinhaça (Quit-V) obtiveram diâmetro médio de $194 \mathrm{~mm}$, enquanto as de quitosana com água destilada (Quit-A) apresentaram $228 \mathrm{~mm}$. Para as partículas de pectina ATM e vinhaça (Pec-V) o diâmetro médio foi de $266 \mathrm{~mm}$ e para as de pectina ATM com água destilada (Pec-A) foi de $429 \mathrm{~mm}$.

Figura 2 - Aspecto visual das partículas produzidas: (A) quitosana com vinhaça (QuitV), (B) quitosana com água destilada (Quit-A), (C) pectina ATM e vinhaça (Pec-V) e (D) pectina ATM com água destilada (Pec-A)
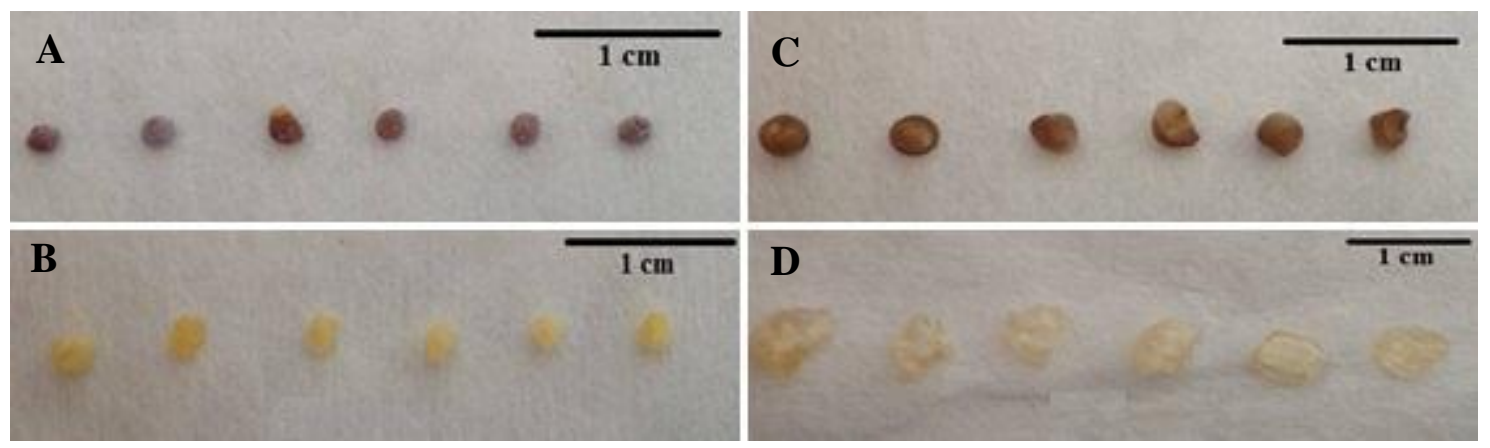
Os resultados de massa solubilizável (MS) em água e em $\mathrm{CaCl}_{2}$ 0,01 $\mathrm{M}$ e dos testes de compressão estão descritos na Tabela 2. Observa-se que a adição de vinhaça provocou um aumento na MS nos dois líquidos testados. Isso pode ser devido a maior concentração de sólidos solúveis na vinhaça que estariam sendo liberados para o meio. Em relação aos dois biopolímeros, as partículas de pectina, em geral, tiveram maior teor de MS. A reticulação da quitosana com o TPP provavelmente foi mais efetiva que a da pectina com $\mathrm{CaCl}_{2}$ em etanol. Isso era esperado uma vez que as pectinas ATM têm baixa interação com íons cálcio, comparado às pectinas de baixo teor de metoxilação (BTM) (Fang et al., 2008). Porém, a solução de pectina BTM com vinhaça não formou um gel adequado e, portanto, não pôde ser utilizada para a formação de partículas (resultados do grupo de pesquisa). A menor estabilização das partículas de pectina ATM, em relação às de quitosana, pôde ser constatada no momento do contato das mesmas com os meios líquidos, onde as partículas de pectina apresentaram intumescimento instantâneo da matriz, enquanto que as de quitosana não sofreram, visualmente, alteração de tamanho. Apesar da menor estabilidade, este intumescimento das partículas de pectina e vinhaça pode ser positivo para a aplicação pretendida, uma vez que estas estruturas conseguiriam reter uma maior quantidade de água no solo, mantendo a umidade por períodos mais longos.

Tabela 2 - Massa solubilizável em água e em $\mathrm{CaCl}_{2}$ e força na compressão das partículas.

\begin{tabular}{|c|c|c|c|}
\hline \multirow{2}{*}{ Formulação } & \multicolumn{2}{|c|}{ MS (g MS/g massa seca)* } & \multirow{2}{*}{ Força na compressão (N)** } \\
\cline { 2 - 3 } & Em água & Em CaCl $\mathbf{~ 0 , 0 1 M}$ & $62,37( \pm 4,36) \mathrm{b}$ \\
Quit-V & $0,49( \pm 0,02) \mathrm{b}, \mathrm{A}$ & $0,34( \pm 0,03) \mathrm{b}, \mathrm{B}$ & $123,77( \pm 14,55) \mathrm{a}$ \\
Quit-A & $0,35( \pm 0,01) \mathrm{c}, \mathrm{A}$ & $0,13( \pm 0,09) \mathrm{c}, \mathrm{B}$ & $35,31( \pm 9,08) \mathrm{c}$ \\
Pec-V & $0,64( \pm 0,01) \mathrm{a}, \mathrm{A}$ & $0,48( \pm 0,03) \mathrm{a}, \mathrm{B}$ & $24,01( \pm 6,31) \mathrm{d}$ \\
Pec-A & $0,51( \pm 0,07) \mathrm{b}, \mathrm{A}$ & $0,22( \pm 0,03) \mathrm{c}, \mathrm{B}$ & \multirow{2}{*}{}
\end{tabular}

MS = massa solubilizável. Média ( \pm desvio padrão) de três* determinações experimentais. Média $( \pm$ desvio padrão) de dez** determinações experimentais. Letras minúsculas diferentes na mesma coluna indicam diferença significativa pelo teste de Scott-Knott $(\mathrm{p}<0,05)$. Letras maiúsculas diferentes na mesma linha para a massa solubilizável indicam diferença significativa pelo teste de Scott-Knott $(\mathrm{p}<0,05)$.

A solução de cloreto de cálcio $0,01 \mathrm{M}$ foi utilizada como forma de simular o efeito da concentração de sais presentes na solução de solo (Van Raij et al., 2001), pensando em uma possível aplicação das partículas como biofertilizante. Observa-se que, para todas as formulações, a MS em cloreto de cálcio $0,01 \mathrm{M}$ foi menor do que o valor observado para a MS em água, indicando uma maior estabilidade das partículas.

As propriedades mecânicas são características importantes, pois elas podem predizer a estabilidade e a funcionalidade dos materiais. Estas medidas podem fornecer informações sobre a magnitude das forças intermoleculares envolvidas na estabilização da matriz polimérica. Os resultados dos testes de resistência mecânica à compressão (Tabela 2) indicam que as partículas de quitosana necessitam de uma maior força de compressão para deformarem e, portanto, são mais resistentes que partículas de pectina ATM. Para a quitosana, a adição da vinhaça provocou uma diminuição na sua força de compressão, indicando uma desestabilização da matriz pelos componentes da vinhaça. Por outro lado, as partículas de pectina ATM com vinhaça tiveram uma força maior em relação as partículas de pectina com água. Esta maior fragilidade da estrutura de partículas de pectina ATM com água pode ser notada em seu formato achatado após a secagem no processo de produção. Acredita-se que o baixo $\mathrm{pH}$ e a presença de açúcares residuais na vinhaça, requisitos importantes no mecanismo de gelificação das pectinas ATM, tenham contribuído para a formação e estabilidade do gel. 


\section{CONCLUSÃO}

Partículas de pectina ATM e de quitosana utilizando vinhaça como solvente foram obtidas com sucesso pela técnica de gotejamento em solução reticulante. A adição da vinhaça provocou um aumento no teor de MS das partículas, quando comparadas às formulações com água. $\mathrm{O}$ menor teor de $\mathrm{MS}$ das partículas em solução de $\mathrm{CaCl}_{2} 0,01 \mathrm{M}$, sugere uma maior estabilidade das partículas no meio simulante de solução de solo. Partículas de quitosana com vinhaça apresentaram menor teor de MS e foram mais resistentes à compressão que as de pectina ATM, indicando um maior grau de reticulação da quitosana com a solução reticulante. A presença da vinhaça conferiu maior estabilidade ao gel de pectina ATM, comparado à formulação com água, provavelmente devido a presença de açúcares residuais na vinhaça. Os resultados, ainda que preliminares, demonstram que as partículas obtidas apresentam potencial para uso como biofertilizante.

\section{REFERÊNCIAS}

CHRISTOFOLETTI, C. A.; ESCHER, J. P.; CORREIA, J. E.; MARINHO, J. F. U.; FONTANETTI, C. S. Sugarcane vinasse: environmental implications of its use. Waste Manage., v. 33, p. 2752-2761, 2013.

DA GLÓRIA, N. A.; RODELLA, A. A. Métodos de análise quantitativa inorgânica em caldo de cana de açúcar; vinhaça e melaço: I. determinação de cálcio, magnésio, potássio, enxofre e fósforo em um mesmo extrato. Anais da Escola Superior de Agricultura Luiz de Queiroz, v. 29, p. 5-17, 1972.

FANG, Y.; AL-ASSAF, S.; PHILLIPS, G. O.; NISHINARI, K.; FUNAMI, T.; WILLIAMS, P. A. Binding behavior of calcium to polyuronates: Comparison of pectin with alginate. Carb. Pol., v.72, p. 334-341, 2008.

IBRAHIM, S.; NAWWAR, G. A. M.; SULTAN, M. Development of bio-based polymeric hydrogel: green, sustainable and low cost plant fertilizer packaging material. J. Environ. Chem. Eng., v. 4, n.1, p.203-210, 2015.

IRISSIN-MANGATA, J., BAUDUIN, G., BOUTEVIN, B.; GONTARD, N., New plasticizers for wheat gluten films. Eur. Pol. J., v.37, p. 1533-1541, 2001.

NAZ, M. Y.; SULAIMAN, S. A. Slow release coating remedy for nitrogen loss from conventional urea: a review. J. Control. Release, v. 225, p.109-120, 2016.

SOARES, M. R.; CASAGRANDE, J. C.; NICOLOSO, R. S. Uso da vinhaça da cana-deaçúcar como fertilizante: eficiência agronômica e impactos ambientais. In: PALHARES, J. C. P.; GEBLER, L. (Eds.). Gestão ambiental na agropecuária. Brasília: Embrapa, Cap. 4, p.145-198, 2014.

TOMLINSON, I. Doubling food production to feed the 9 billion: A critical perspective on a key discourse of food security in the UK. J. Rural Studies, v. 29, p.81-90, 2011.

TOMOVIĆ, N. S.; TRIFKOVIĆ, K. T.; RAKIN, M. P.; RAKIN, M. B.; BUGARSKI, B. M. Influence of compression speed and deformation percentage on mechanical properties of calcium alginate particles. Chem. Ind. Chem. Eng. Q., v. 21, n. 3, p. 411-417, 2015.

VAN RAIJ, B.; ANDRADE, J. C., CANTARELLA, H.; QUAGGIO, J. A. Análise Química para Avaliação da Fertilidade de Solos Tropicais. Campinas: Instituto Agronômico de Campinas - IAC. 2001. 285 p. 